\title{
The Development of the MeDALL Core Questionnaires for a Harmonized Follow-Up Assessment of Eleven European Birth Cohorts on Asthma and Allergies
}

\author{
Cynthia Hohmann ${ }^{a}$ Mariona Pinart ${ }^{b-d, h} \quad$ Christina Tischer ${ }^{\mathrm{e}} \quad$ Ulrike Gehring ${ }^{1}$ Joachim Heinrich ${ }^{\mathrm{e}}$ \\ Inger Kull ${ }^{g, w}, x$ Eric Melén ${ }^{g, x}$ Henriette A. Smit ${ }^{y}$ Maties Torrent ${ }^{d, z}$ Alet H. Wijga ${ }^{f}$ Magnus Wickman ${ }^{g, x}$ \\ Claus Bachert ${ }^{i}$ Karin C. Lødrup Carlsen ${ }^{j}$ Kai-Håkon Carlsen ${ }^{j}$ Carsten Bindslev-Jensen ${ }^{k}$ Esben Eller ${ }^{k}$ \\ Ana Esplugues $^{d, l, m}$ Maria Pia Fantini ${ }^{n}$ Isabella Annesi-Maesano ${ }^{\circ}$ Isabelle Momas ${ }^{\text {p } q}$ Daniela Porta ${ }^{r}$ \\ Maria Vassilakis ${ }^{\mathrm{s}}$ Dagmar Waiblinger ${ }^{\mathrm{t}} \quad$ Jordi Sunyer $^{\mathrm{b}-\mathrm{d}, \mathrm{h}}$ Josep M. Antó ${ }^{\mathrm{b}-\mathrm{d}, \mathrm{h}}$ Jean Bousquet ${ }^{\mathrm{u}, \mathrm{v}}$
} Thomas Keil ${ }^{\mathrm{a}, 2}$ The MeDALL Study Group

${ }^{\mathrm{a}}$ Institute of Social Medicine, Epidemiology and Health Economics, Charité - Universitätsmedizin Berlin, Germany; ${ }^{\mathrm{b}}$ Centre for Research in Environmental Epidemiology (CREAL), ' IMIM (Hospital del Mar Medical Research Institute), and d CIBER Epidemiología y Salud Pública (CIBERESP), Barcelona, Spain; ${ }^{\mathrm{e}}$ Institute of Epidemiology, German Research Centre for Environmental Health, Helmholtz Zentrum München, Neuherberg, Germany; ${ }^{f}$ Centre for Prevention and Health Services Research, National Institute for Public Health and the Environment (RIVM), Bilthoven, The Netherlands; ${ }^{9}$ Institute of Environmental Medicine, Karolinska Institutet,

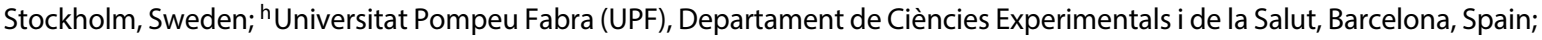
'Upper Airway Research Laboratory, University of Ghent, Ghent, Belgium; 'Department of Paediatrics, Oslo University Hospital and University of Oslo, Oslo, Norway; ${ }^{k}$ Department of Dermatology and Allergy Centre, Odense University Hospital, Odense, Denmark; 'Division of Environment and Health, Centre for Public Health Research - CSISP, and ${ }^{m}$ Faculty of Nursing, University of Valencia, Valencia, Spain; ${ }^{n}$ Department of Medicine and Public Health, Alma Mater Studiorum, University of Bologna, Bologna, Italy; ${ }^{\circ}$ EPAR

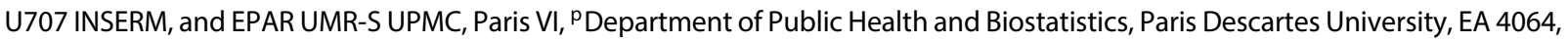
and 9 Paris Municipal Department of Social Action, Childhood and Health, Paris, France; 'Department of Epidemiology, Regional Health Service Lazio Region, Rome, Italy; ${ }^{5}$ Department of Social Medicine, Faculty of Medicine, University of Crete, Heraklion,

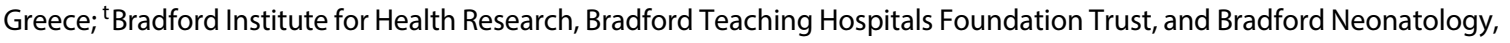
Bradford Royal Infirmary, Bradford, UK; ' University Hospital, Department of Respiratory Diseases, Hôpital Arnaud de Villeneuve, Montpellier, and "Inserm, CESP Centre for Research in Epidemiology and Population Health, U1018, Respiratory and Environmental

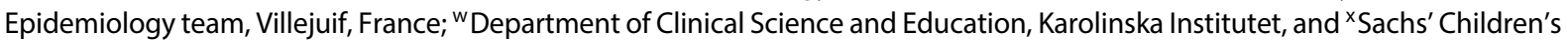
Hospital, Stockholm, Sweden; ' J Julius Centre for Health Sciences and Primary Care, University Medical Centre Utrecht, Utrecht, The Netherlands; ${ }^{2}$ Menorca Health Area, Ib-Salut, Mahon, Spain; ${ }^{1}$ Institute for Risk Assessment Sciences, Utrecht University, Utrecht, The Netherlands; ${ }^{2}$ Institute of Clinical Epidemiology and Biometry, University of Würzburg, Würzburg, Germany

\section{Key Words}

European birth cohorts · Asthma · Allergy · Questionnaire assessment $\cdot$ Harmonization $\cdot$ MeDALL

\begin{abstract}
Background: Numerous birth cohorts have been initiated in the world over the past 30 years using heterogeneous methods to assess the incidence, course and risk factors of
\end{abstract}

asthma and allergies. The aim of the present work is to provide the stepwise proceedings of the development and current version of the harmonized MeDALL-Core Questionnaire (MeDALL-CQ) used prospectively in 11 European birth cohorts. Methods: The harmonization of questions was accomplished in 4 steps: (i) collection of variables from 14 birth cohorts, (ii) consensus on questionnaire items, (iii) translation and back-translation of the harmonized English MeDALL-CQ into 8 other languages and (iv) implementa-

\begin{tabular}{ll}
\hline KARGER & $\begin{array}{l}\text { ( 2014 S. Karger AG, Basel } \\
1018-2438 / 14 / 1633-0215 \$ 39.50 / 0 \quad \text { Karger }\end{array}$ \\
$\begin{array}{l}\text { E-Mail karger@karger.com } \\
\text { www.karger.com/iaa }\end{array}$ & $\begin{array}{l}\text { This is an Open Access article licensed under the terms of the } \\
\text { Creative Commons Attribution-NonCommercial 3.0 Un- } \\
\text { ported license (CC BY-NC) (www.karger.com/OA-license), } \\
\text { applicable to the online version of the article only. Distribu- } \\
\text { tion permitted for non-commercial purposes only. }\end{array}$
\end{tabular}

Correspondence to: Dr. Cynthia Hohmann, Dr. Thomas Keil Institute of Social Medicine

Epidemiology and Health Economics, Charité - Universitätsmedizin Berlin Luisenstrasse 57, DE-10117 Berlin (Germany)

E-Mail cynthia.hohmann@charite.de, thomas.keil@charite.de 
tion of the harmonized follow-up. Results: Three harmonized MeDALL-CQs ( 2 for parents of children aged 4-9 and 14-18, 1 for adolescents aged 14-18) were developed and used for a harmonized follow-up assessment of 11 European birth cohorts on asthma and allergies with over 13,000 children. Conclusions: The harmonized MeDALL follow-up produced more comparable data across different cohorts and countries in Europe and will offer the possibility to verify results of former cohort analyses. Thus, MeDALL can become the starting point to stringently plan, conduct and support future common asthma and allergy research initiatives in Europe.

(c) 2014 S. Karger AG, Basel

\section{Introduction}

Numerous cohorts focusing on asthma and allergy have been initiated in the world over the past 30 years, most of them focusing on the evaluation of incidence, course and risk factors of asthma and allergies $[1,2]$. In Europe, the costs of persistent asthma were estimated at EUR 19.3 billion and most costs were due to young patients aged 15-30 years [3]. The questionnaires used by many cohorts to assess symptoms of asthma and rhinitis included several questions based on those developed and validated in the worldwide International Study of Asthma and Allergies in Childhood (ISAAC) [4]. Although the order and/or wording of the ISAAC questions were usually slightly modified, questions on asthma and allergic rhinitis were homogeneously assessed across European birth cohorts. On the other hand, the assessment of other allergic phenotypes (e.g. eczema, sensitization to aero- and food allergens), pulmonary development and possible determinants of allergic diseases, including dietary habits and environmental exposures, were rather heterogeneous $[1,2]$. MeDALL attempts to increase the amount of harmonized questions beyond those included in the ISAAC questionnaire or those which might have been included in the ISAAC questionnaire but were not frequently used by the cohorts in the last years.

Since 2004, several research initiatives funded under the EU Framework Program for Research and Technological Development FP6-FP7 have attempted to identify, compare and evaluate pooled data from existing European birth cohorts [5]: GA ${ }^{2}$ LEN (Global Allergy and European Network, FP6) [6], ENRIECO (Environmental Health Risks in European Birth Cohorts, FP7) [7], CHICOS (Developing a Child Cohort Research
Strategy for Europe, FP7) and MeDALL (Mechanisms of the Development of Allergy, FP7) [8-10]. Combined analyses across birth cohorts result in larger sample sizes and increased statistical power, and broaden the diversity of environmental exposure assessments and facilitate research on underlying mechanisms explaining heterogeneous results among the cohorts [11].

Combining birth cohort data can be done retrospectively on historical data or prospectively by using the same core questionnaire and standard operating procedures for physical examinations. The collaborative MeDALL project aims to integrate epidemiological and clinical research and to identify inherited and environmental factors associated with the onset of allergy in children $[8,9]$. Within this project, combined analyses of historical data from 14 European birth cohorts are underway. Moreover, MeDALL harmonizes a core assessment for follow-up of 11 birth cohorts in order to prospectively collect data on asthma and allergies. It is of importance that historical and prospective questions are interoperable to compare data.

Questionnaires for birth cohorts are collected according to the age at examination. In adolescents questionnaires are completed by the participants and their parents, whereas in school children (under 10 years) questionnaires are given to the parents only. In MeDALL, participants of 8 birth cohorts are older than 13 years (in the following referred to as the 'older birth cohorts') and participants of 6 others are younger than 10 years (in the following referred to as the 'younger birth cohorts') at the time of the harmonized follow-up.

The aim of the present work is to provide the stepwise proceedings of the development and current version of the MeDALL-Core Questionnaire (MeDALL-CQ) used prospectively in over 13,000 children. More specifically: (1) different working steps and the item selection process for the harmonized MeDALL-CQ are described and (2) the 3 English MeDALL-CQs, namely the parental (MeDALL-PQ, 14-18 years) and adolescent (MeDALLAQ, 14-18 years) versions for the older birth cohorts and the parental questionnaire (MeDALL-PQ, 4-9 years) for the younger birth cohorts are presented in the online supplementary material (for all online suppl. material, see www.karger.com/doi/10.1159/000357732). (3) Translations in 8 languages and standard operating procedures for clinical examinations are available but not included in the present paper. They can be retrieved by contacting the corresponding author. The harmonized MeDALL follow-up is ongoing and resulting data will be presented in following publications. 
Table 1. The eight birth cohorts (participant age 14-18 years) that took part in the development of a harmonized MeDALL-CQ

\begin{tabular}{|c|c|c|c|c|c|}
\hline Birth cohort & Country/region & $\begin{array}{l}\text { Year of } \\
\text { recruitment }\end{array}$ & $\begin{array}{l}\text { Size at } \\
\text { recruitment, } \\
\mathrm{n}\end{array}$ & $\begin{array}{l}\text { Age at MeDALL } \\
\text { follow-up, years }\end{array}$ & $\begin{array}{l}\text { Size at MeDALL } \\
\text { follow-up } \\
\text { (expected), n }\end{array}$ \\
\hline PIAMA-NHS & The Netherlands/North, West and Central & $1996-1997$ & 3,963 & $15-17$ & 2,500 \\
\hline GINIplus & Germany/Munich, Wesel & $1996-1998$ & 5,991 & $14-17$ & 2,050 \\
\hline LISAplus & Germany/Munich, Wesel, Leipzig, Bad Honnef & 1997-1998 & 3,097 & $15-17$ & 1,050 \\
\hline DARC & Denmark/Odense & $1998-1999$ & 562 & $14-15$ & 450 \\
\hline ECA & Norway/Oslo & $1992-1993$ & 3,754 & $16-17$ & 550 \\
\hline MAS & $\begin{array}{l}\text { Germany/Berlin, Düsseldorf, Mainz, Freiburg, } \\
\text { Munich }\end{array}$ & 1990 & 1,314 & 20 & 790 \\
\hline
\end{tabular}

Six of the cohorts took part in the common MeDALL follow-up assessment and two birth cohorts (ECA, MAS) had a follow-up based on own funding.

Table 2. The six birth cohorts (participant age 4-9 years) that took part in the development of a harmonized MeDALL-CQ and the common MeDALL follow-up assessment

\begin{tabular}{llrrrr}
\hline Birth cohort & Country/region & $\begin{array}{l}\text { Year of } \\
\text { recruitment }\end{array}$ & $\begin{array}{l}\text { Size at } \\
\text { recruitment, follow-up, years } \\
\text { n }\end{array}$ & $\begin{array}{l}\text { Age at MeDALL } \\
\text { follow-up } \\
\text { (expected), n }\end{array}$ \\
\hline BiB & UK/Bradford & $2007-2010$ & 13,776 & 4 & 1,500 \\
INMA & Spain/Valencia, Sabadell, Guipuzkoa & $2004-2008$ & 3,768 & $4-7$ & 1,100 \\
PARIS & France/Paris & $2003-2006$ & 4,115 & 8 & 900 \\
RHEA & Greece/Heraklion, Crete & $2007-2008$ & 1,497 & 4 & 900 \\
ROBBIC & Italy/Rome, & 2003 & 709 & $8-9$ & 700 \\
& Italy/Bologna & 2003 & 654 & 5 & 500 \\
\hline
\end{tabular}

Five of the cohorts took part in the common MeDALL follow-up assessment and one birth cohort (EDEN) had a follow-up based on own funding, which did not use the MeDALL-CQ.

\section{Materials and Methods}

Members of MeDALL-CQ

Members of 8 older European MeDALL birth cohorts (AMICSMenorca, BAMSE, DARC, ECA, GINIplus, LISAplus, MAS and PIAMA-NHS) developed and approved a common harmonized MeDALL-CQ for adolescent participants (MeDALL-AQ, 1418 years) and their parents (MeDALL-PQ, 14-18 years; table 1).

Members of 6 younger European MeDALL birth cohorts (BiB, EDEN, INMA, PARIS, ROBBIC and RHEA) developed and approved a common harmonized MeDALL-PQ, for children aged 4-9 years (table 2 ).

\section{Development of MeDALL-CQ}

The harmonization of questions was conducted for 8 major sections (table 3 ) in 4 steps: (i) collection of variables from 14 birth cohorts, (ii) consensus on questionnaire items, (iii) translation and back-translation of the harmonized English MeDALL-CQ in 8 other languages and (iv) implementation of the harmonized follow-up (fig. 1).

During the process, it was important to reach a consensus on the inclusion of the questionnaire items by achieving a maximal harmonization between the cohorts and, at the same time, not to endanger longitudinal comparisons within each cohort. The MeDALL-CQ included core questions but also shared additional questions and gave the cohorts the opportunity to include a number of their own individual questions. This questionnaire, available in 9 different languages, was used prospectively by 11 MeDALL birth cohorts.

Sections and Item Selection for the MeDALL-CQ

Health Outcomes

The definitions for asthma, rhinitis and eczema were based on a MeDALL consensus meeting held in Barcelona, June 2011 [12]. 


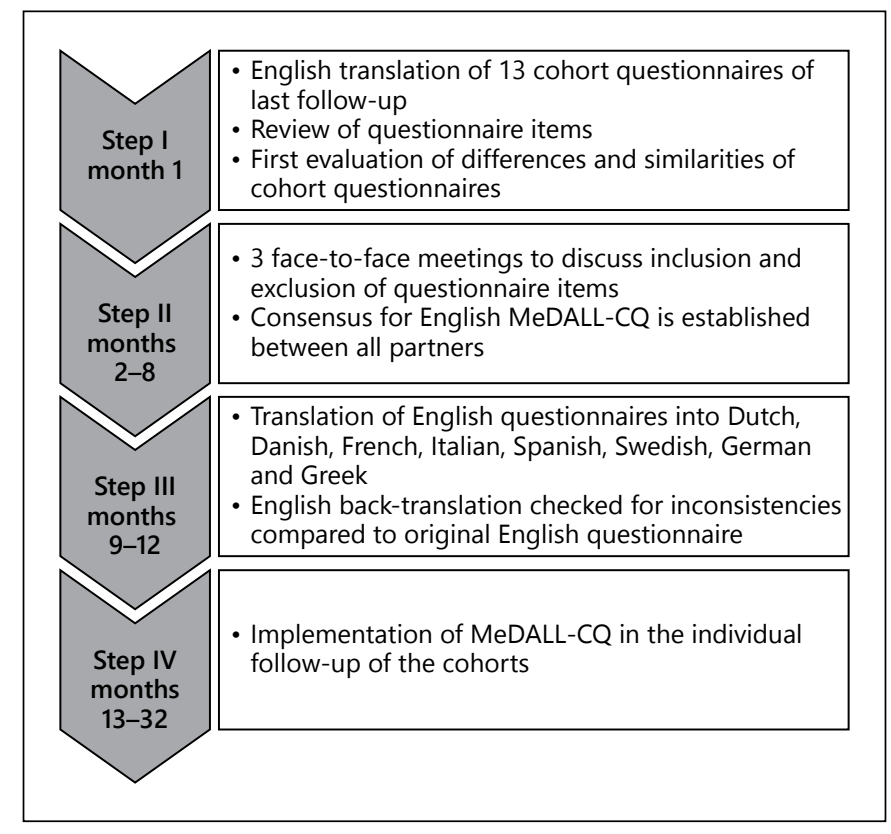

Fig. 1. Overview of the different working steps of the development of the harmonized MeDALL-Core Questionnaires (CQ) currently used by 11 European birth cohorts.

Table 3. Major sections of the common MeDALL questionnaire

1. Asthma

2. Allergic rhinitis

3. Eczema

4. Socio-demographic questions

5. Nutrition

6. Indoor environment (dampness/mold, tobacco smoke exposure, air pollution)

7. Lifestyle factors (physical activity, smoking, alcohol and drugs)

8. Puberty development

Asthma. ISAAC questions on wheezing symptoms [4], questions on doctor's diagnosis, hospital visits and medication intake were chosen to assess the prevalence and severity of asthma. Based on the decisions of the working group the adolescent core questionnaire, AQ, contained additional questions on tightness of chest and shortness of breath since these symptoms are also considered as 'key indicators for considering a diagnosis of asthma' [13]. The triad of respiratory symptoms (wheezing and/or tightness of chest and/or shortness of breath), doctor's diagnosis and medication intake was used for a questionnaire-based definition of asthma in children and adolescents $[8,14,15]$. In the MeDALL-AQ, a visual analog scale was used to estimate asthma and its impact on daily life, as these scales are more sensitive to small outcome differences than, for example, ordinal scales are [16], and may be relevant to assess the control of asthma [8]. Depending on country-specific differences, the wording of the question regarding an asthma diagnosis by a doctor might be adapted (e.g. additional questions for doctor's diagnosis of obstructive, asthmatic or spastic bronchitis for German-speaking countries). Questions for which it was unclear whether the judgment about the illness was based on a doctor's diagnosis or on self-diagnosis were not incorporated. Moreover, the MeDALL-CQs gave the cohorts the opportunity to include a number of cohort-specific questions to allow for consistency with earlier follow-ups. For the asthma section, this comprises questions on seasonal variations of symptoms, chronic obstructive lung disease and further details of medication intake. These questions were included in the section for optional use.

Rhinitis. The presence of rhinitis can be assessed by questionnaire assessment, while allergic rhinitis can be assessed by a questionnaire on nasal symptoms and the demonstration of an IgEmediated sensitization to specific allergens (using skin-prick testing and/or specific serum IgE assays) only. Seasonal and perennial rhinitis were distinguished by the inclusion of ISAAC questions on current (last 12 months) and seasonal rhinitis symptoms [4]. In addition, questions about medication use and prior allergen-specific immunotherapy were included. If only current symptoms are assessed, children with medication intake might wrongly be categorized as healthy because the extent of their currently experienced symptoms might be profoundly reduced by the treatment received. Questions based on ARIA were used to assess the duration and severity of allergic rhinitis [17]. In the MeDALL-AQ, 14-18 years, questions on rhinosinusitis were included based on suggestions in the European Position Paper on Rhinosinusitis and Nasal Polyps ( $\mathrm{EP}^{3} \mathrm{OS}$ ) emphasizing the importance of the current lack of knowledge about the incidence and prevalence of rhinosinusitis in European countries, and the need for 'large-scale epidemiologic research' $[18,19]$.

Eczema. The diagnosis of eczema by a doctor and the prevalence, severity and seasonal variations of eczema symptoms were assessed by means of items from the ISAAC questionnaire [4] and the Williams' and UK working criteria [20]. Moreover, questions on contact dermatitis were included. Concerning eczema severity, the POEM (Patient-Oriented Eczema Measure) [21] was part of the supplemental questionnaire which assesses self-reported recent eczema severity over the last 7 days. As for wheezing and rhinitis symptoms in epidemiological studies, the corresponding POEM-based eczema severity questions referred to the last 12 months. This method of assessing self-reported eczema severity will be validated by two of the birth cohorts during the course of MeDALL (BAMSE and DARC).

\section{Possible Determinants of Allergic Diseases}

Parental Allergies. Family history is a relevant risk factor of allergic diseases and regular assessments of parental allergies are necessary to record different patterns which might influence children's allergies [22]. Thus, the MeDALL-PQ contains questions on the diagnosis of asthma, rhinitis and eczema of both parents, also including age at onset of the disease and the differentiation between the doctor's diagnosis and self-diagnosis. Although information on parental allergies was already collected in former questionnaires (for most cohorts at birth) the differentiation between a self-diagnosis versus a doctor's diagnosis was lacking in most cohorts.

Nutrition. The birth cohorts participating in MeDALL are geographically spread across the European continent from Norway 
and Sweden in the north to Spain and Greece in the south, covering various climatic and cultural regions with heterogeneous nutritional habits $[23,24]$. Due to these considerable differences in diet among the MeDALL birth cohort study participants, and also reflected by the different instruments used in previous nutritional assessments in each of the cohorts, harmonized food questions could not be identified. However, all MeDALL cohorts assessed data on the food-item level by using cohort-specific food frequency questionnaires. Common questions for the MeDALL-CQs were agreed upon by the MeDALL partners to assess self- and parentreported allergic reactions to food, including the age at first reaction, the type of allergic reaction and current allergic reactions to food items.

Indoor Environment. 'Cooking with gas' was included in the MeDALL-PQ and the inclusion of variables such as kitchen ventilation or the 'presence of other sources of combustion products' were not expected to explain additional variance when investigating respiratory health outcomes [25]. Three questions on 'dampness and/or mold within the home' were adapted from the LISAplus and GINIplus cohorts aiming to follow-up a previous metaanalysis that suggested a possible link with wheezing and allergic rhinitis [15]. The parents were considered to be a more reliable source of information concerning the indoor environment at home than the adolescents. Active and passive tobacco smoke exposure, however, needed to be included in both the parental MeDALL-PQ as well as the adolescent MeDALL-AQ, since parents are not likely to know (exactly) their teenaged children's tobacco exposure outside the home.

Lifestyle Factors. In the MeDALL-AQ, 14-18 years, questions on physical activity, smoking, alcohol and drug consumption were included. For this purpose, the International Physical Activity Questionnaire (IPAQ) [26] was adapted to the needs of an epidemiological study. Instead of asking for physical activity during the last 7 days, which could be useful in cross-sectional or short-term intervention studies, the corresponding IPAQ-based MeDALL questions asked for physical activity during a typical week in the last 12 months in summer and, separately, in winter. It is planned to validate this assessment in the German LISA birth cohort by using accelerometers. Besides active smoking, questions on passive smoking at indoor locations were added to the MeDALL-PQ, distinguishing between second-hand smoke exposures 'at home' and 'not at home'. Alcohol and drug consumption were assessed each by two questions asking for the type of alcohol/drug and the amount of intake as glasses per week or times of intake in the last 12 months, adapted from the KiGGS survey [27]. The unit 'number of sips' used before by some of the cohorts was not considered as a valid proxy for current drinking behavior in adolescents. No consensus was reached about questions on binge drinking, but the following 2 questions were recommended for optional use: 'have you ever drunk that much alcohol that you have been dizzy or sick afterwards? If yes, how often in the last 12 months?' and 'have you ever drunk that much alcohol that you could not remember everything from the day before?', which have been used in former questionnaires by the cohorts GINIplus and LISAplus.

Puberty Development. In the MeDALL-ACQ, puberty development was assessed by the Pubertal Development Scale (PDS) [28]. The prospectively collected data since birth in the MeDALL cohorts provides the unique possibility to investigate determinants of the postulated sex-switch in the prevalence of asthma and allergic diseases during puberty [29].
Other Questions. The MeDALL-AQ contained questions on height, weight and school degree/level of schooling of the adolescent participants. Although allergies might play a minor role in adolescents' job choices [30], items inquiring whether the choice of schooling programs is affected by allergic diseases were included so that the prevalence of current allergic symptoms would not be underestimated due to the avoidance of known allergens. Furthermore, this question could give an idea of the severity of the allergic disease and its impact on the choices of the adolescent regarding everyday life. The items of this section were extracted from former cohort questionnaires and agreed on by all MeDALL birth cohorts.

\section{Results}

The three MeDALL-CQs consisted of 8 sections, of which each was divided into a core section and supplementary questions which remained optional for the cohorts. The complete MeDALL-CQs are presented in online supplemantary figure 1-3. Please see online supplementary figure 4 for references of the single items of the MeDALL-CQs.

The MeDALL-AQ, 14-18 years, included 66 core-section items and 19 optional items for adolescents (online suppl. fig. 1). The parent-reported MeDALL-PQ, 1418 years, included 50 core-section items and 5 optional items (online suppl.fig.2). The parent-reported MeDALLPQ, 4-9 years, included 56 core-section items and 37 optional items (online suppl. fig. 3).

\section{Discussion}

The MeDALL-CQ is, to our knowledge, the first attempt to develop a multilingual common core questionnaire for birth cohorts in allergy and asthma. It has been constructed using a rigorous stepwise process and it is now used in 11 birth cohorts in 9 European countries. It can be expanded to other countries in the world with relatively minor adaptation. This MeDALL-CQ is interoperable with historical data of the 14 MeDALL cohorts, making it possible to compare part of the data across several time points (table 4 ).

\section{Limitations}

In some sections of the questionnaire country-specific differences were so profound, for example in the section on nutrition, that it was decided that harmonization was impossible. Also, questions about educational status had to be adapted for each country. The other sections were judged to be suitable for the harmonization process and 


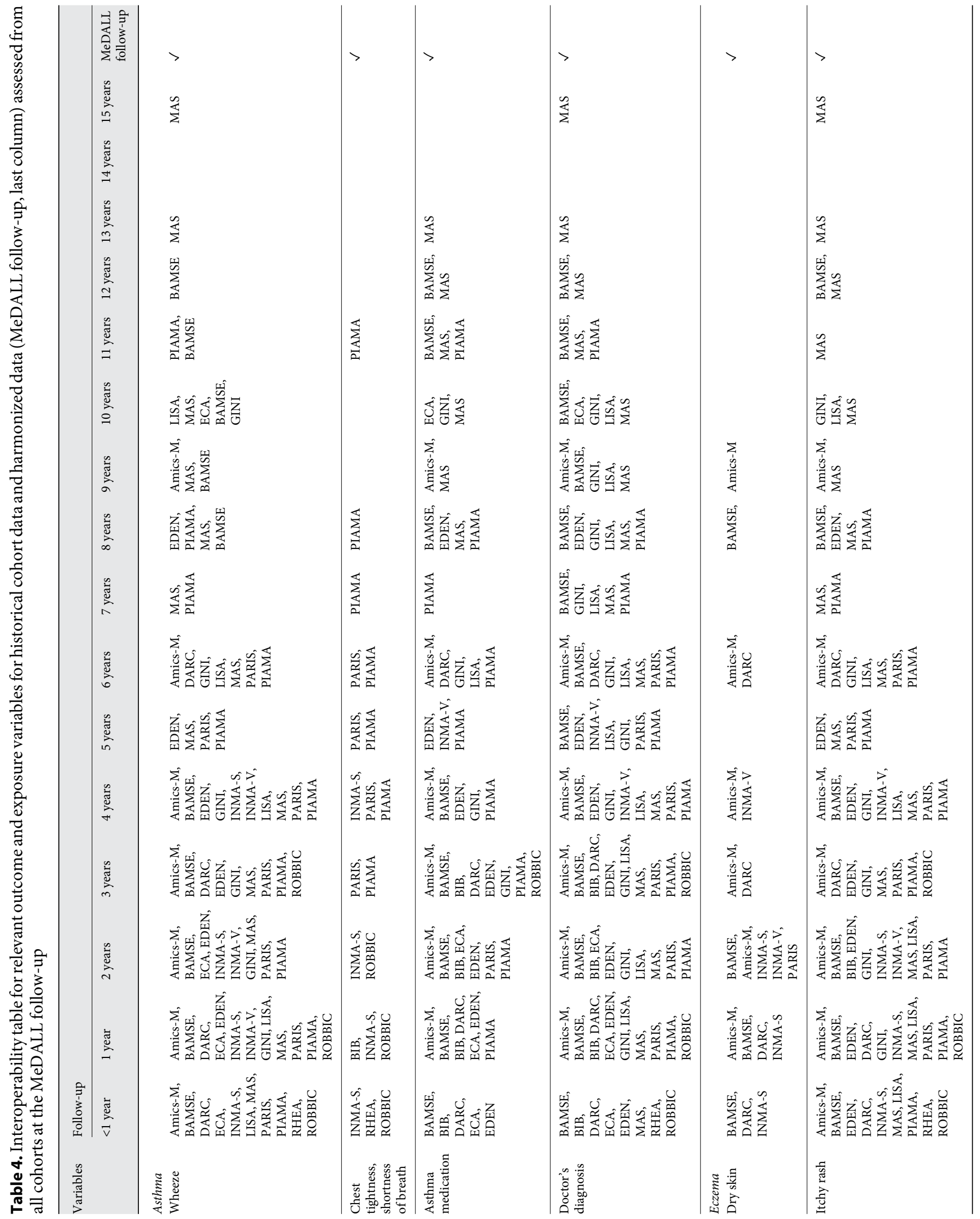




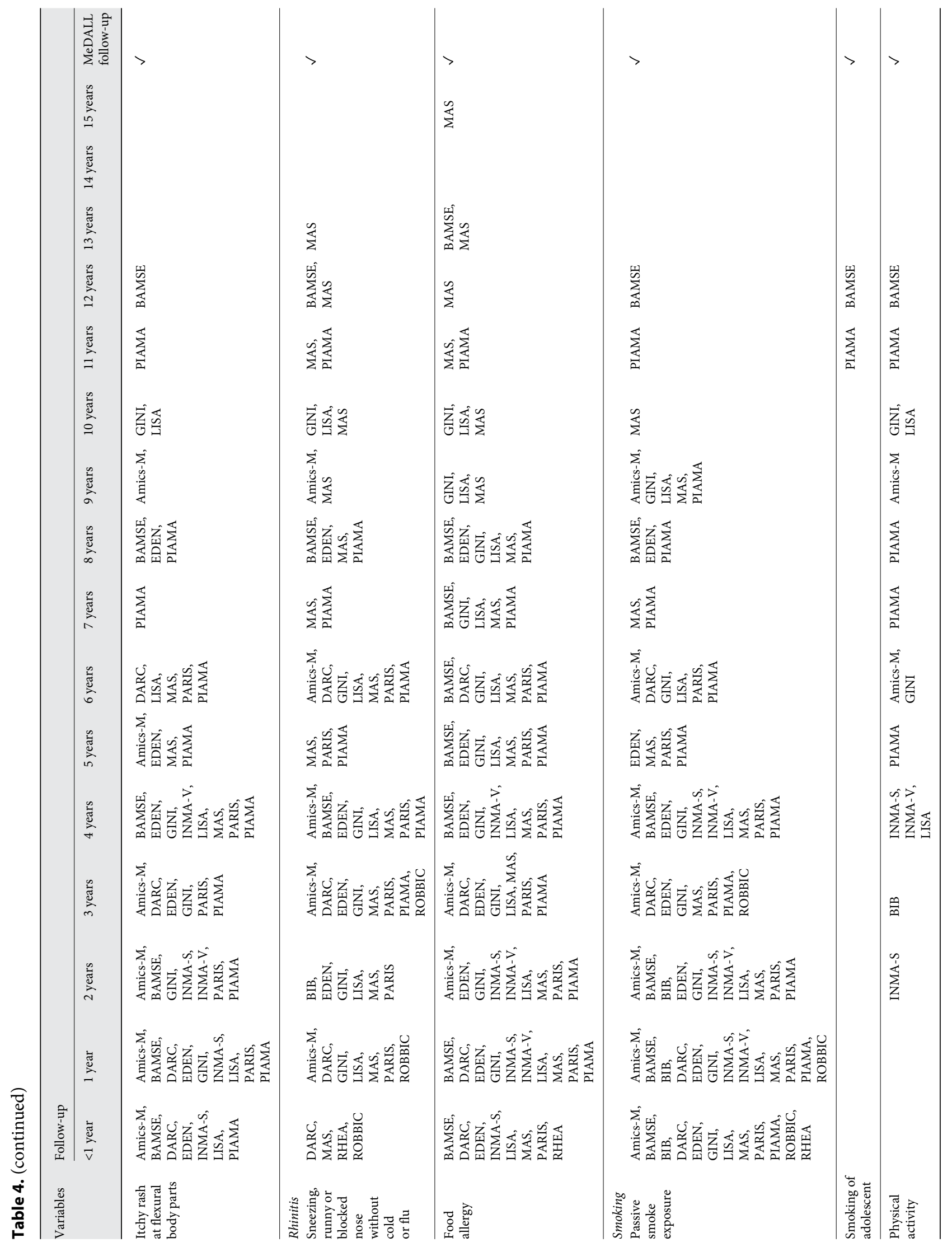




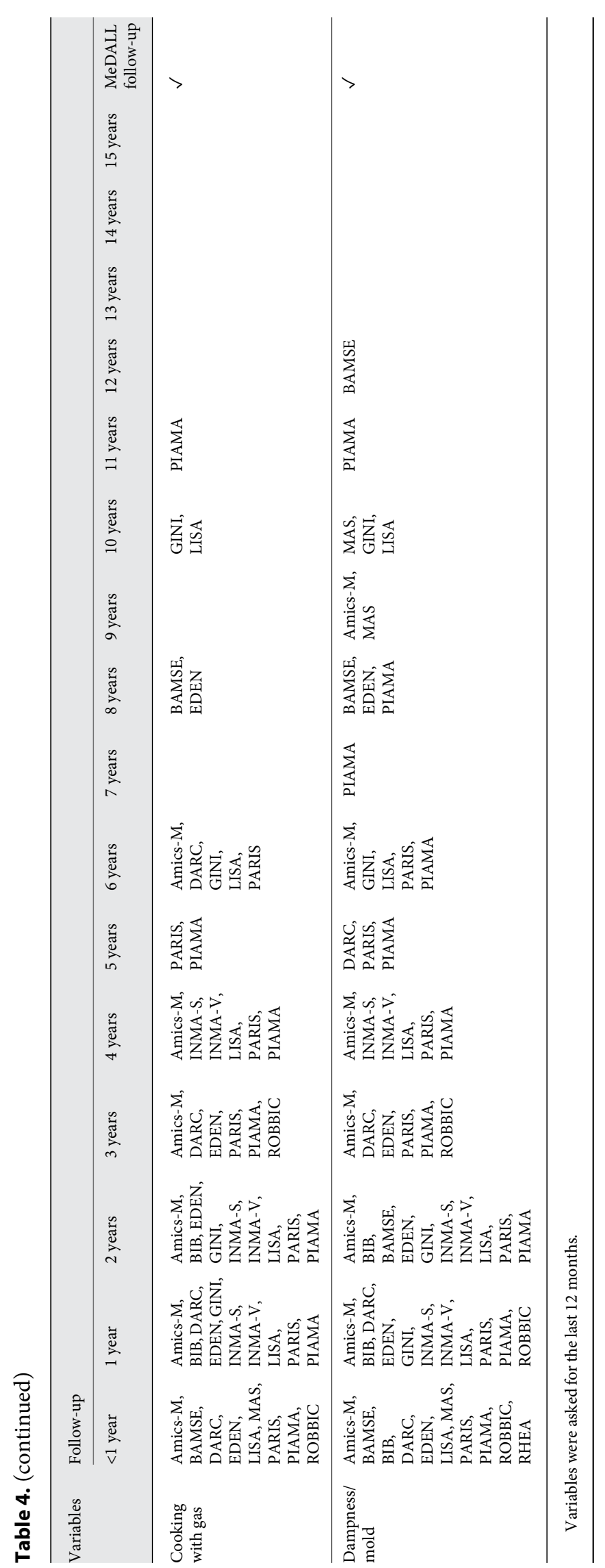

the translations and back-translations of questionnaires were found to be correctly translated into the 8 other languages. However, it cannot be excluded that slightly different wording chosen in other languages has led to different interpretations. This might not be the case for questions about factual knowledge, such as 'how many cigarettes do you smoke?', but rather for questions on medical conditions such as 'wheeze', for which the general public understanding might be limited, and could lead to different answering behavior among participants. Also, asking for eczema - 'have you (mother or father) ever had eczema?' - highly depends on the patients' understanding of the actual wording, which might also differ depending on the language used.

Moreover, the order of the harmonized questions within the questionnaire differs between the cohorts. As the cohorts should have the possibility to include their own questions, the harmonized questions are not asked in one exclusive part of the questionnaire, but are instead integrated in different sections of the cohorts' own questionnaires. Not only the order, but also the way in which the questionnaires can be filled out varies in terms of using paper and pencil versus online completion. Furthermore, the age of the adolescents to which the questionnaire is given showed a discrepancy between the cohorts (14-18 years). No data will be retrieved for the age group 11-13 years within the MeDALL project. If the MeDALLCQ is used in future studies, different ages of participants and the order of questions should be considered as one source of variability of the results.

The questionnaires were developed by the extraction of questions from former questionnaires, clinical experience, experience with specific questions in the cohort questionnaires and consensus in the research group, and, so far, a validation of the core questionnaires is missing. The MeDALL-CQ is an instrument under constant development and will be modified according to future experience and results.

\section{Strengths and Generalizability}

The harmonized MeDALL questionnaire, measuring a variety of health outcomes and possible determinants of allergies in childhood and adolescence, is publicly available in 9 different languages (Danish, Dutch, English, French, German, Greek, Italian, Spanish and Swedish) and has been used for the age groups 4-9 and 14-18 years.

For the 6 older birth cohorts, historical childhood data and the MeDALL-CQ will be harmonized to analyze longitudinal exposure-response relationships from childhood up to adolescence within the MeDALL project. The 
separated parental and adolescent questionnaire versions allowed detailed use of the knowledge of each participant. While the parents were expected to give more reliable data on questions referring to conditions throughout the adolescent's life, housing situation and topics such as parental allergies, the adolescents were thought to be the more reliable source for information on current allergy symptoms, which can also occur without the knowledge of the parent, and on environmental exposures such as smoke exposure, which do not take place at home.

The 6 younger birth cohorts provided data up to 9 years of age in the current MeDALL follow-up. If the MeDALL-CQ is continuously used in the coming years, in the long-run these will be the cohorts with prospectively harmonized data, available from early childhood up to adolescence. Time-consuming data harmonization processes will be unnecessary in the future.

The construction of the ISAAC questionnaire was a major achievement in the field of asthma and allergy assessment, it encouraged networking between European cohorts, as in $\mathrm{GA}^{2} \mathrm{LEN}$, and was the base on which many data harmonization projects such as ENRIECO have been built. MeDALL is taking this approach one step further by including a bigger pool of harmonized variables and using existing European birth cohorts as a data source with already existing historical data and further followups planned for the coming years. MeDALL will offer a harmonized assessed multicountry sample of over 13,000 parent-child pairs.

\section{Conclusion}

The harmonized follow-up of 11 European birth cohorts in MeDALL will produce more comparable data across different cohorts and countries in Europe. In addition, all participating cohorts are allowed to include additional questions and instruments following their own special research interests, so that focused knowledge about specific local issues is obtained. The harmonized follow-up, however, does not reduce the need to harmonize historical data of the participating cohorts for combined longitudinal analyses.

Understanding geographical and time patterns of allergic diseases is a challenge. Results from the harmonized MeDALL follow-up will provide more insight into true differences or similarities between cohorts and/or countries in Europe. This new harmonized assessment will offer the possibility to verify results of former combined analyses for which otherwise extensive efforts of data harmonization are necessary. Thus, MeDALL can become the starting point to stringently plan, conduct and support future common asthma and allergy research initiatives in Europe.

\section{Acknowledgments}

Mechanisms of the Development of Allergy (MeDALL) is funded by the European Union in the 7th Framework program, grant agreement No. 261357.

\section{References}

$\checkmark 1$ Keil T, Kulig M, Simpson A, Custovic A, Wickman M, Kull I, et al: European birth cohort studies on asthma and atopic diseases. I. Comparison of study designs - a GALEN initiative. Allergy 2006;61:221-228.

$\checkmark 2$ Keil T, Kulig M, Simpson A, Custovic A, Wickman M, Kull I, et al: European birth cohort studies on asthma and atopic diseases. II. Comparison of outcomes and exposures - a GA2LEN initiative. Allergy 2006;61:11041111.

3 Accordini S, Corsico AG, Braggion M, Gerbase MW, Gislason D, Gulsvik A, Heinrich J, Janson C, Jarvis D, Jõgi R, Pin I, Schoefer Y, Bugiani M, Cazzoletti L, Cerveri I, Marcon A, de Marco R: The cost of persistent asthma in Europe: an international population-based study in adults. Int Arch Allergy Immunol 2013;160:93-101.

4 Asher MI, Keil U, Anderson HR, Beasley R, Crane J, Martinez F, et al: International Study of Asthma and Allergies in Childhood
(ISAAC): rationale and methods. Eur Respir J 1995;8:483-491.

5 Bousquet J, Anto J, Sunyer J, Nieuwenhuijsen M, Vrijheid M, Keil T, MeDALL Study Group, CHICOS Study Group, ENRIECO Study Group, GA ${ }^{2}$ LEN Study Group: Pooling birth cohorts in allergy and asthma: European Union-funded initiatives - a MeDALL, CHICOS, ENRIECO, and GA ${ }^{2} L E N$ joint paper. Int Arch Allergy Immunol 2013;161:110.

6 Lodrup Carlsen KC, Roll S, Carlsen KH, Mowinckel P, Wijga AH, Brunekreef B, et al: Does pet ownership in infancy lead to asthma or allergy at school age? Pooled analysis of individual participant data from 11 European birth cohorts. PLoS One 2012;7:e43214.

7 Vrijheid M, Casas M, Bergström A, Carmichael A, Cordier S, Eggesbo M, et al: European birth cohorts for environmental health research. Environ Health Perspect 2012;120: 29-37.
8 Antó JM, Pinart M, Akdis M, Auffray C, Bachert C, Basagaña $\mathrm{X}$, et al: Understanding the complexity of IgE-related phenotypes from childhood to young adulthood: a Mechanisms of the Development of Allergy (MeDALL) seminar. J Allergy Clin Immunol 2012;129:943-954.

-9 Bousquet J, Anto J, Auffray C, Akdis M, Cambon-Thomsen A, Keil T, et al: MeDALL (Mechanisms of the Development of Allergy): an integrated approach from phenotypes to systems medicine. Allergy 2011;66:596-604.

10 Bousquet J, Anto JM, Demoly P, Schünemann HJ, Togias A, et al: Severe chronic allergic (and related) diseases: a uniform approach - a MeDALL - GA²LEN - ARIA position paper. Int Arch Allergy Immunol 2012;158:216-231.

11 Hohmann C, Govarts E, Bergström A, Cordier S, Eggesbø M, Guxens M: Joint data analyses of European birth cohorts: two different approaches. WebmedCentral Epidemiology 2012;3:WMC00386 
12 Pinart M, Maier D, Gimeno-Santos E, Sola I, Garcia-Aymerich J, Guerra S, et al: Systematic review protocol to define classical IgEassociated diseases from birth to adolescence: the MeDALL Study. WebmedCentral Allergy 2012;3:WMC003408.

13 National Institutes of Health, National Heart, Lung and Blood Institute, National Asthma Education and Prevention Program: Expert panel report 3: guidelines for the diagnosis and management of asthma. 2007. http://www. nhlbi.nih.gov/guidelines/asthma/asthgdln. pdf (accessed August 10, 2012).

-14 Neumann A, Hohmann C, Orsini N, Pershagen $\mathrm{G}$, Eller E, Fomsgaard Kjaer $\mathrm{H}$, et al: Maternal smoking in pregnancy and asthma in preschool children - a pooled analysis of eight birth cohorts. Am J Respir Crit Care Med 2012;186:1037-1043.

$\checkmark 15$ Tischer C, Chen CM, Heinrich J: Association between domestic mould and mould components, and asthma and allergy in children: a systematic review. Eur Respir J 2011;38:812824.

16 Paul-Dauphin A, Guillemin F, Virion JM, Briançon S: Bias and precision in visual analogue scales: a randomized controlled trial. Am J Epidemiol 1999;150:1117-1127.

-17 Bousquet J, van Cauwenberge P, Khaltaev N, et al: Allergic rhinitis and its impact on asthma. J Allergy Clin Immunol 2001;108(5 suppl): 147-334.
18 Fokkens W, Lund V, Mullol J: European position paper on rhinosinusitis and nasal polyps: chronic rhinosinusitis with or without nasal polyps (CRSwNP or CRSsNP). Rhinology 2012;50(suppl 23):1-298.

19 Fokkens W, Lund V, Mullol J: EP ${ }^{3}$ OS 2007: European position paper on rhinosinusitis and nasal polyps 2007 - a summary for otorhinolaryngologists. Rhinology 2007;45:97101.

20 Williams HC, Burney PG, Pembroke AC, Hay RJ: The UK Working Party's Diagnostic Criteria for Atopic Dermatitis. III. Independent hospital validation. Br J Dermatol 1994;131: 406-416.

21 Charman CR, Venn AJ, Williams HC: The patient-oriented eczema measure development and initial validation of a new tool for measuring atopic eczema severity from the patients' perspective. Arch Dermatol 2004; 140:1513-1519.

22 Alford SH, Zoratti E, Peterson EL, Maliarik M, Ownby DR, Johnson CC: Parental history of atopic disease: disease pattern and risk of pediatric atopy in offspring. J Allergy Clin Immunol 2004;114:1046-1050.

23 Roos G, Johansson L, Kasmel A, Klumbiené J, Prättälä R: Disparities in vegetable and fruit consumption: European cases from the north to the south. Public Health Nutr 2001;4:35-43.

24 Beer-Borst S, Hercberg S, Morabia A, Bernstein MS, Galan P, Galasso R, et al: Dietary patterns in six European populations: results from EURALIM, a collaborative European data harmonization and information campaign. Eur J Clin Nutr 2000;54:253-262.
25 Willers SM, Brunekreef B, Oldenwening M, Smit HA, Kerkhof M, De Vries H, et al: Gas cooking, kitchen ventilation, and asthma, allergic symptoms and sensitization in young children - the PIAMA study. Allergy 2006;61: 563-568.

26 Craig CL, Marshall AL, Sjöström M, Bauman AE, Booth ML, Ainsworth BE, et al: International physical activity questionnaire: 12-country reliability and validity. Med Sci Sports Exerc 2003;35:1381-1395.

27 Lampert T, Thamm M: Tabak- Alkohol- und Drogenkonsum von Jugendlichen in Deutschland: Ergebnisse des Kinder- und Jugendgesundheitssurveys (KiGGS). Bundesgesundheitsbl Gesundheitsforsch Gesundheitsschutz 2007;50:600-608.

28 Carskadon MA, Acebo C: A self-administered rating scale for pubertal development. J Adolesc Health 1993;14:190-195.

29 Almqvist C, Worm M, Leynaert B, Working Group of GA ${ }^{2}$ LEN WP 2.5 Gender: Impact of gender on asthma in childhood and adolescence: a GA²LEN review. Allergy 2008;63:4757.

30 Radon K, Huemmer S, Dressel H, Windstetter D, Weinmayr G, Weiland S, et al: Do respiratory symptoms predict job choices in teenagers? Eur Respir J 2006;27:774-778. 